\title{
Changes in JASMS: Carol Robinson to Edit New Critical Insights Feature and Joe Loo to Serve as New Associate Editor for Protein Mass Spectrometry
}

W e are pleased to announce two important editorial changes for your Journal of the American Society for Mass Spectrometry (JASMS). The first is a new feature to be known as a "Critical Insight," which will be edited by Carol Robinson, Cambridge University in the UK, who has been with the editorial team for eight years, serving as associate editor and handling many of our submissions in protein chemistry and proteomics. Carol will continue to serve as associate editor, but she will take charge of the Critical Insights feature.

The purpose of Critical Insights is to explore current topics in mass spectrometry and to provide an informed view into issues not normally reported in primary research papers. We hope that Critical Insights, which may often present controversial viewpoints, will be thought-provoking and interesting to you. In this month's issue Lloyd Smith considers the pro and cons of charge reduction electrospray. In an upcoming issue, Roman Zubarev provides critical insight into electron capture/transfer vs collisionally activated/induced dissociations. We hope that you enjoy reading this new feature.

The second change is necessitated by the first. JASMS must continue to publish articles in protein biochemistry and proteomics, an important area for our subject. Therefore, we are increasing the editorial team by adding Joseph Loo as a new associate editor to handle many of the submissions in the protein area. Although this is our first formal announcement of these changes, Carol and Joe have been working in their new capacities since August 2007.

Joe is Professor of Biological Chemistry, David Geffen School of Medicine, and of Chemistry \& Biochemistry at the University of California, Los Angeles (UCLA), and he is the Director of UCLA Jonsson Comprehensive Cancer Center Mass Spectrometry and Proteomics Technology Center. He is also a member of UCLA/DOE Laboratory for Genomics and Proteomics, the UCLA Molecular Biology Institute, and the UCLA Jonsson Comprehensive Cancer Center.

Joe has considerable expertise in the mass spectrometry characterization of proteins and their post-translational modifications and is the author of over 160 scientific publications. He has been on the Editorial
Board of the Journal of the American Society for Mass Spectrometry Bioconjugate Chemistry, Analytical Chemistry (A-Page), and Chemical \& Engineering News and currently he serves on the Editorial Advisory Board for Rapid Communications in Mass Spectrometry. In 20002002, he served on the Board of Directors for the ASMS.

His research interests include the development of bioanalytical methods for the structural characterization of proteins and their application for proteomics and disease biomarkers. He is also interested in development and application of electrospray ionization mass spectrometry for the study of non-covalently-bound macromolecular complexes and their interactions with other binding partners and ligands, an interest he shares with Carol. At UCLA, Joe teaches a course for undergraduate students titled "Chemical Instrumentation" and a graduate-level course titled "Proteomics and Mass Spectrometry."

Before Joe joined UCLA, he was Group Leader of the Biological Mass Spectrometry and Proteomics Teams at Parke-Davis Pharmaceutical (currently Pfizer Global Research), Ann Arbor, MI. He worked at Warner-

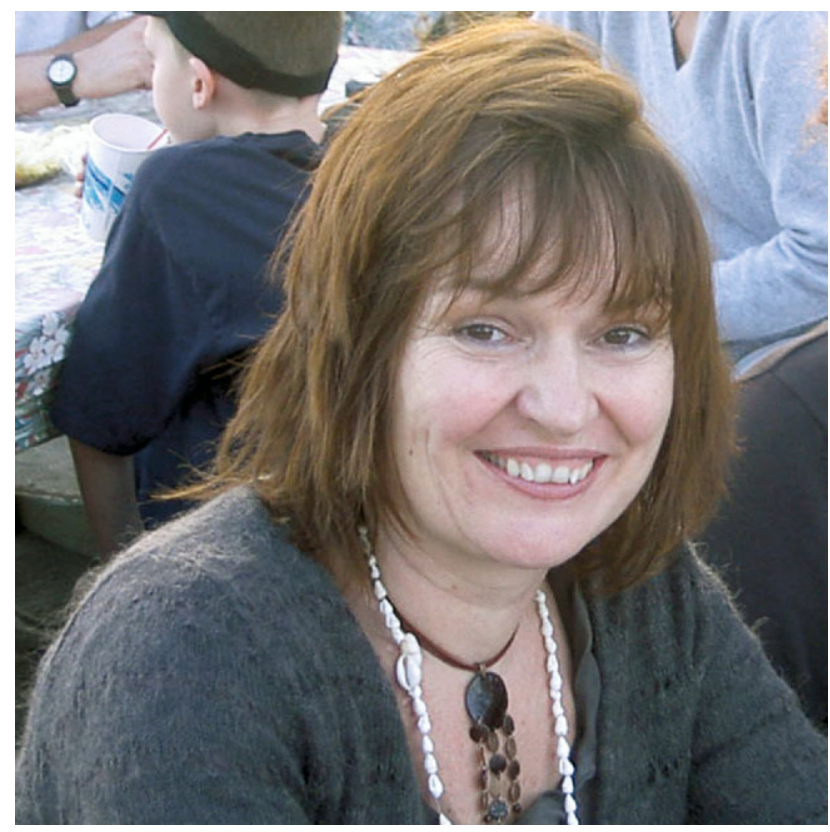

Carol Robinson at the 2005 Pacifichem Conference in Hawaii. 


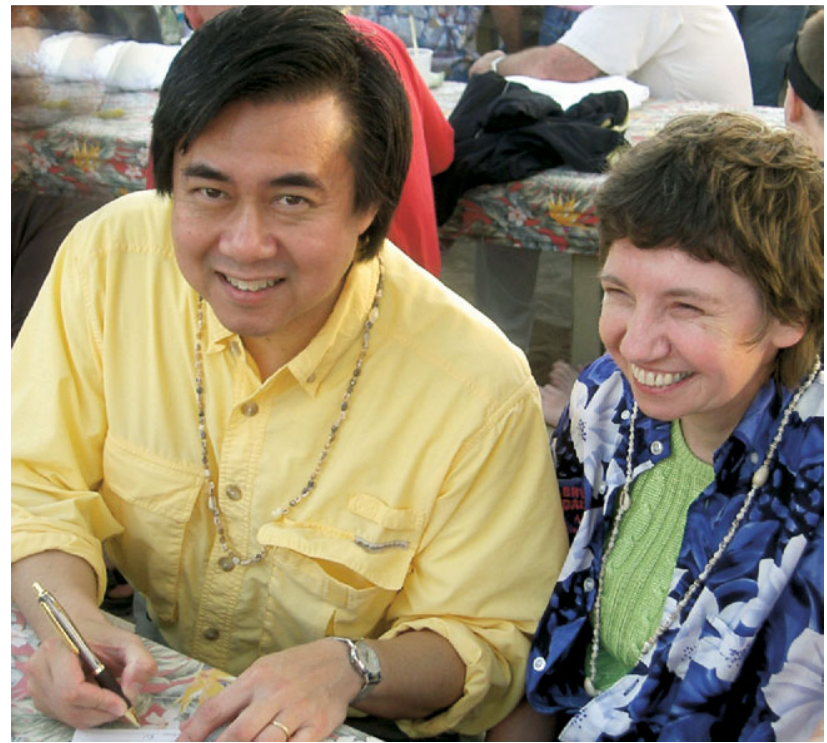

Joe Loo and his wife, Rachel Ogorzalek Loo, signing autographs at the 2005 Pacifichem Conference.
Lambert/Parke-Davis/Pfizer for nearly 10 years before moving to UCLA. His extensive experience in industry and academics will serve well JASMS's interest in protein chemistry and proteomics.

Joe received his BS degree in chemistry from Clarkson University (Potsdam, NY), and his Ph.D. in analytical chemistry from Cornell University in 1987 with Professor Fred W. McLafferty, working on the development of Fourier transform mass spectrometry for bioanalytical applications. He carried out postdoctoral research at Pacific Northwest National Laboratory, Richland, WA, with Dr. Richard D. Smith on the development of electrospray ionization mass spectrometry and capillary electrophoresis for protein characterization.

We welcome Joe to the editorial team and thank Carol for accepting the challenge of arranging and editing the new Critical Insights articles.

Michael L. Gross Editor 